\title{
E-Commerce Adoption in Saudi Arabia: an Assessment of International, Regional and Domestic Web Presence
}

\author{
Mutlaq B. Alotaibi \\ Vice Dean, College of Computer and Information Sciences, Imam University, Saudi Arabia \\ Email: motaibi@imamu.edu.sa
}

\begin{abstract}
Electronic Commerce (E-Commerce) has a growing potential in Saudi Arabia, due to widespread use of the internet and the maturity of the Information Technology (IT) infrastructure. The purpose of this paper is to assess the quality of E-Commerce websites in Saudi Arabia, using a proposed evaluation instrument. To achieve this aim, six E-Commerce websites were selected for evaluation and then categorized into three categories: domestic, regional and international. Each category consisted of two E-Commerce websites, with the international website category considered as a benchmark. The six websites were evaluated by sixty participants $(n=60)$ with good web design experience, following a set of guidelines offered by the evaluation instrument. The evaluation instrument described six key evaluation factors: appearance, content, organization, interaction, customer-focus and assurance. Each factor was evaluated by several indicators using a five-point scale ranging from not applicable (0) to very strong (4). To unify the views of all evaluators, a technique was introduced which would show the way in which each indicator was assessed based on several checklists (questions). The results therein revealed that international websites were of higher quality than regional and domestic websites with regard to all aspects of web evaluation. In addition, the quality of regional websites outweighed that of domestic websites with regard to appearance, content, organization, customer-focus and as surance, but not interaction.
\end{abstract}

Index Terms - E-Commerce, Customer-focus, Content, Saudi Arabia, Web Evaluation, Appearance

\section{Introduction}

Web presence offers several advantages to businesses, due to the role it plays in turning visitors into customers [1]. Evaluation of web presence is a growing area of interest for both practitioners and researchers [2]. Several evaluation methods have been proposed, but fro $m$ an E-Commerce point of view, these methods are often general or difficult to apply [3]. In addition, the nature of the E-Commerce setting calls for the development of a tailored scale devoted to measuring particular elements related to online environments [4]. Little attention has previously been paid to evaluating commercial web presence in different markets: domestic, regional and international. Therefore, this investigation was conducted to fill this gap in the current knowledge. Pursuing this aim, evaluation frameworks were discussed and criteria proposed in the current literature were presented in order to develop a tailored web evaluation instrument. A web evaluation instrument was introduced to show how websites should be evaluated. This instrument incorporated several evaluation indicators and checklists representing six web evaluation factors developed with further consideration to the application domain, i.e. ECommerce environments. Based on a withinparticipants design, a group of evaluators carried out the web presence evaluation by rating each evaluation factor using a five-point scale. Results of domestic web presence were compared against those for regional and international web presence in order to determine the position of E-Commerce practices in Saudi Arabia.

This study placed emphasis on the evaluation of web presence in the context of E-Commerce and, in particular, on identifying the key dimensions for commercial web presence in Saudi Arabia, in order to highlight potential improvement opportunities. It was noteworthy that the concept of quality, particularly on the web, is complex in nature [5]. Therefore, the identification of factors by which the quality of web presence is determined is central in evaluating the quality of any online environment [6]. These evaluation factors were: appearance, content, organization, interaction, customer-focus and assurance. The evaluation of these factors in three different markets (international, regional and domestic) would provide significant contributions to the field and open up new directions for further research. This study thus contributed to the current literature on E-Commerce, proposing a web evaluation instrument developed to measure the quality of commercial web presence, with particular focus on the assessment of international, regional and domestic markets. It contributed to the current literature on ICT adoption in Saudi Arabia, as it identified the position of Saudi E-Commerce practices 
in comparison with international key players and regional practices.

The remainder of this paper is organized as follows: web evaluation methods are discussed in section two. Section three presents the web evaluation instrument proposed for this research. Experimental study is described in section four, while section five presents results. Section six presents the discussion and the conclusion is provided in section seven.

\section{Web Evaluation Methods}

This section reviews and identifies critical elements of E-Commerce website development and design. In recent studies, a great deal of emphasis has been put into understanding how web presence can be evaluated. Several academic researchers proposed or considered different classifications of web evaluation methods. For example, Law et al. [7] categorized website evaluation approaches into counting, automated, numerical computation, user judgment and combined methods. The counting approach evaluates the richness of the website content, whereas the user judgment method assesses user satisfaction and perceptions. The automated method evaluates the website using software systems, whereas the numerical method uses mathematical functions to compare different website performances. The combined method uses more than one approach to evaluate selected websites. Another categorization by Chiou et al. [3] relied on an extensive review of the literature. Chiou et al. [3] categorized website evaluation methods into three categories: Information Systems (IS), marketing and combined approaches. The IS approach incorporated technologyrelated factors, such as usability, accessibility, navigation and information quality. The marketing approach focused on marketing dimensions, such as advertising, promotion, online transaction, order confirmation and customer relationships. The combined approach included a mixture of both IS and marketing factors. It was revealed that recent evaluations relied on the combined approach and factors were evaluated by ranking lists [3]. In brief, different techniques and methods were employed to facilitate effective web presence evaluations.

Web presence evaluation methods relied on either ranking websites based on an empirically validated scale or proposing a modified instrument. It is important to consider that website evaluation goals differ from those for usability testing. In fact, usability testing aims to identify usability problems within a system, while website evaluation is used to rank a set of selected websites [8]. It is commonly agreed that web evaluation relies on developed and validated scales. Law et al. [7] highlighted that a great deal of research adopts an existing model or instrument to evaluate websites. In fact, Lin et al. [9] argued that modification of web evaluation models is usually required, especially for those generically developed to evaluate websites regardless of the type of service they offer. The proposed evaluation factors differ based on the perspective from which each author looks at the evaluation. For example, based on five web requirement areas, Fitzpatrick [10] proposed an instrument that included five evaluation factors: visibility, creditability, intelligibility, engagibility and differentiation. The factors consisted of several characteristics and a checklist of enablers. The author looked at website evaluation from a software quality point of view and proposed general factors that lacked a domain-specific focus. Mich et al. [11] proposed a website evaluation model with six evaluation factors: identity, content, services, location, management and usability. The model can be applied to different website types, due to its general purpose design. However, an in-depth understanding of commercial web presence requires a tailored evaluation model. Therefore, Yang et al. [12] developed a context-specific scale that incorporated fourteen dimensions representing forty-two items to measure the quality of online shopping. The fourteen dimensions were responsiveness, credibility, ease of use, reliability, convenience, communication, access, competence, courtesy, personalization, continuous improvement, security/privacy, collaboration and aesthetics. In summary, proposed web evaluation methods were either generic with a less domain-specific focus or tailored models developed for a particular application domain.

Scholarly research into web presence evaluation has considered the modification and extension of existing models, such as ServQual [13] and WebQual [14]. For example, Barnes and Vidgen [15] applied an extended WebQual instrument to assess online auctions. The instrument incorporated seven factors: website navigation, website look and feel, information quality, trustworthiness, customer relationship, selling quality and buying quality. It is noteworthy that this study lacked a representative sample. Another example based on the WebQual method [16] proposed a tailored model to evaluate bookstore websites with several key factors: usability, design, information, trust and empathy. This study revealed that intuitively critical E-Commerce features were ranked as of the most concern to customers, as opposed to technical and softer features that appeared to be less important. Based on a ServQual scale, Long and McMellon [17] developed a fivedimensional scale to measure perception of E-Service quality. The five factors of the scale were tangibility, assurance, reliability, purchase process and responsiveness. In another study based on the ServQual scale, Lin et al. [9] introduced a web evaluation scale to evaluate 70 selected Chinese websites. The scale consisted of 16 marketing functions categorized into five key factors: tangibles, reliability, responsiveness, assurance and empathy. Furthermore, Li and Suomi [18] proposed eight evaluation factors to measured EService quality based on the ServQual model. The factors included website design, reliability, fulfillment, 
security and responsiveness. Another study by Yang et al. [19] proposed an E-Service quality model representing six dimensions: reliability, responsiveness, competence, ease of use, security and product portfolio. In summary, existing models, such as ServQual and WebQual, serve as a baseline for introducing tailored and modified models designed to evaluate web presence and service quality of different websites.

In the context of E-Commerce, scale development either incorporated domain-specific factors or considered the different phases of the purchasing process. For example, Schubert [20] proposed an extended version of the Web Assessment Method (WAM) [21] which integrates the Technology Acceptance Model (TAM) [22]. It evaluated perceived quality of commercial web presence in two business -toconsumer (B2C) sectors: Electronic Retailing (ERetailing) and online banking. The empirical evaluation was carried out by twenty students recruited to rate four companies from each sector according to three main factors: ease of use, usefulness and trust. The three factors were assessed during four transaction phases: information, agreement, settlement and after-sales with the community component taken into account as a supporting element. The results revealed that after-sales services and general web presence features, such as appearance, availability, interactivity, trustworthiness, were perceived as important to customers in both sectors. However, information quality was perceived to be the most important to E-Retailing users, while aftersales services were perceived as the most important to online banking users. Although this study was useful to illustrate the position of a company within the sector and compared its profile with the best practice in that sector, it lacked diversity and the sample was not representative. Another example is the study by Yang [23] into the perception of service quality in ECommerce. The study examined the difference between two groups: buyers and visitors. Reliability was found to be more important to E-Commerce frequent buyers, whereas perception of the website was perceived as more important for visitors. To measure E-Service quality in E-Retailing Collier and Bienstock [24] proposed a web evaluation model representing process, outcome and recovery dimensions. Another study by Tan and Tung [25] proposed a framework for designing effective websites with four key factors: perceived ease of use, perceived usefulness, perceived playfulness and attractiveness. Based on TAM dimensions, 20 web designers were interviewed to highlight important factors in developing B2C websites. In brief, trends in evaluating commercial web presence put great emphases on incorporating either steps related to the purchasing process, factors derived from the domain of buying and selling over the internet, or a co mbination of both.

Several academic researchers conducted web evaluations from a strategic point of view. Others evaluated websites in terms of the absence or presence of application context considerations. In the strategic web evaluation, Chiou et al. [26] employed a strategic website evaluation framework to evaluate online tourism websites during a five-stage process. The author used a hierarchical evaluation structure consisting of several goals, objectives and criteria. This approach was comprehensive and gave an impression that it could reflect a genuine picture, but it was generally difficult to apply on a large scale. With the application context taken into consideration, a study by Basu [27] presented a three-dimensional approach to assessing website quality focusing on the nature and functionality of the website. The three dimensions were business context, process and website-specific factors. In the business context, determination of the website's main purpose was considered, whereas the process dimension identified the core processes of that context. The website-specific factors introduced a mixture of technical and marketing elements, such as search, authentication, validation and price discovery, payment, logistics, customization and usability issues. Furthermore, Parasuraman [28] developed a multipleitem scale for measuring E-Service quality using four factors: efficiency, fulfillment, system availability, and privacy. It was noteworthy that other factors, such as responsiveness, compensation, and contact, were placed in different scales to measure the quality perception of users who had non-routine encounters. In addition, a study by [29] suggested functionality, reliability and usability as three main factors for evaluating online business. This included evaluation of offered services, security of transactions and quality of user-website interaction. This method focused on internet banking environments and would be difficult to apply to other fields. On the other hand, Hasan and Abuelrub [30] proposed a generic model which could be applied to different sectors and included several web evaluation factors: content, design, organization and userfriendliness. Each factor was assessed by a set of indicators that consisted of a checklist of enablers. This study proposed a model that targeted online businesses regardless of the type of services offered. However, application and validation of this model was not empirically examined. In summary, web evaluation can be generic, strategic or domain-specific.

\section{Research Instrument}

The decision to use generic or domain-focused web evaluation instruments involves trade-offs. The generic web evaluation method lacks the consideration of all aspects related to E-Commerce contexts, but it is applicable to various domains. Domain-specific instruments put more emphasis on factors related to the domain and could be inappropriate when applied elsewhere. In this study, using a mixture of generic and domain-specific models was considered, in addition to the focus on the interaction dimension. The proposed web assessment instrument consisted of six key factors: 
appearance, content, organization, interaction, customer-focus and assurance. Each factor was determined by several indicators, as shown in Table 1.

Table 1: Proposed Web Evaluation Instrument

\begin{tabular}{|c|c|c|}
\hline Factor & Items & Brief description \\
\hline Appearance & 13 & Attractive and balanced appearance with proper colours and texts \\
\hline Attractive appearance & 3 & Website is innovative, has emotional appeal and aesthetic effects \\
\hline Balanced appearance & 4 & Website appearance is appropriate, balanced and consistent \\
\hline The use of colours & 2 & Website employs good text and background colours \\
\hline The use of text & 4 & The text is readable and consistent with multiple headings \\
\hline Content & 15 & Content is updated, relevant, accurate and multi-cultural \\
\hline Updated content & 3 & Content is up-to-date, frequently updated and time of update is shown \\
\hline Relevant content & 5 & Content is comprehensive, informative and fit to cust omer needs \\
\hline Accurate content & 3 & Information is accurate, precise and its source is presented, with no errors \\
\hline Multilanguage content & 2 & Website is suit able for different cultures and uses different languages \\
\hline Content presentation & 2 & Information is presented in an objective manner with different formats \\
\hline Organization & 14 & Website is properly named and logically organized \\
\hline Website identity & 3 & Names are easily remembered and meaningful, logo is presented \\
\hline Mapping & 3 & Navigation menu, website map and current page title display \\
\hline Consistency & 2 & Website is logically structured. Layout and behaviour is consistent \\
\hline Navigation and links & 3 & Good navigation, clear communication and working links \\
\hline Index & 3 & Website categories are shown and can be accessed from the index \\
\hline Interaction & 20 & Interactive features, elements and techniques are incorporated \\
\hline Adoption of multimedia & 3 & Website uses multimedia elements effectively and efficiently \\
\hline Adaptability & 5 & Interfaces can be adapted by hiding and changing the position of elements \\
\hline Self-adaptation & 4 & Website presents personalized contents, pages and products \\
\hline The use of audio & 3 & Audio, speech and non-speech elements are employed during the interaction \\
\hline The use of avatars & 5 & Speaking Avat ars with facial expressions or bo dy gestures are employed \\
\hline Customer-focus & 18 & Focus is put on customer needs, relationships and community \\
\hline Feedback mechanisms & 3 & Website allows feedback through customer rating, reviews and suggestions \\
\hline Loyalty programmes & 4 & Rewards are offered for acquiring or retaining cust omers \\
\hline Help and support & 4 & Website provides help features, such as FAQ, search and what's new \\
\hline Purchasing facilities & 4 & Services are offered to support purchasing, e.g. return, refund, dispute \\
\hline Reliability & 3 & Website is efficient (download time), properly operating and available \\
\hline Assurance & 15 & Customer trust and confidence on the website is supported \\
\hline Trust & 4 & Website legitimacy, reputation and payment system. Threats are determined \\
\hline Security & 4 & Security signs and certificates, support and policy \\
\hline Privacy & 4 & Privacy seals and policy are presented. Privacy practice is guaranteed. \\
\hline Authority & 3 & Creditability and copyright are identified \\
\hline
\end{tabular}

Website appearance focused on the visual design of the website, as it was considered important to gain customer attention. This factor was evaluated by four indicators: attractive appearance, balanced appearance, the use of colours and the use of text [16, 25, 27, 30-32] First, attractive appearance was evaluated by three checklists: website innovativeness, beauty and emotional appeal [16, 27]. Secondly, balanced appearance was evaluated by several checklists: appropriateness, the balanced use of text, images and colours and using images that serve functional purposes [27]. Thirdly, evaluation of the use of colours suggested that light colours should be used for the background and the number of text colours used should not exceed four within the same page $[25,31,32]$. Finally, the use of text was assessed by four checklists: consistency and readability of text font, size and style, the use of multiple headings and avoidance of extensive use of capital letters $[25,30]$. In summary, four indictors, each of which consisted of several checklists, were devoted to evaluating website appearance.

Evaluation of the website content involved assessing whether information was updated, relevant, accurate and presented by different languages and methods [10, 16 , 27]. There were five indicators for content 
evaluation: updated content, relevant content, accurate content, multi-language content and content presentation. First, updated content denoted the website responsibility to keep information up-to-date and properly maintained [16, 27]. Secondly, the content provided had to be seen as sufficient, understandable and fit customers' needs and requirements [16]. In fact, information about organizational objectives, history, products and services should be presented, as well as photography of organization facilities [16]. Thirdly, content accuracy denoted whether content was precise and free from spelling and grammatical errors [10, 16]. It also involved the identification of information sources Fourthly, the website should be suitable for customers from different countries and should present information using different languages [10]. Finally, the website should present information using alternative formats, such as PDF, video, audio etc. [16]. Information should also be presented in an objective manner without any political, cultural or institutional bias [16]. In summary, the website content was evaluated by its update status, relevancy, accuracy, presentation methods and languages.

Good organization of a website improves the quality of the work and critical user performance aspects [16]. Excellent organization facilitates easy access to the website and its content through internal links, external lin ks and/or search engines. Organization was evaluated by five indicators: website identity [11], mapping, consistency, navigation and links, and index [10, 16, 27]. First, it was suggested that website name and domain name should be easy to remember and meaningful - related to the service offered [9-11]. In addition, the website logo should be clearly displayed. Secondly, the website should offer a navigation menu, website map and current page title display [10, 33, 34]. Thirdly, websites should be logically organized, structured and consistent with regard to layout, behaviour and communication, especially error messages [27, 29, 35]. Fourthly, the website should be easy to use by facilitating good navigation [36]. This included links that should be always available and which change colour after being visited [10, 16, 27]. Finally, website categories should be well-organized, explicitly shown and can be accessed from the index $[10,35]$. In summary, organization was assessed by website identity, mapping, consistency, navigation and links, and index.

Interaction was evaluated by five main indicators: adoption of multimedia, adaptability, self-adaptation, the use of audio and the use of avatars $[10,11,16,27$, 34, 36-41]. First, adoption of multimedia elements, such as images, video and audio, was seen as an advantage to the website $[11,27]$. Ho wever, these ele ments should be effectively employed, especially in terms of selecting the right ones. It was also considered that adoption of multimedia elements should be efficient, not affecting download time [34, 41]. Secondly, adaptability was evaluated using five checklists relating to the how the interface could be adapted: by hid ing interface elements or changing their position $[16,36]$, by offering the user the ability to change the order of displayed items, the position of interface elements, the order of presented interface elements and by customizing products and services. Thirdly, the assessment of self-adaptation included four checklists: personalized products, messages and recommendations, adaptive pages and contents and catering to different users [16, 18]. Fourthly, the use of audio was evaluated by three checklists: use of speech, musical stimuli and auditory icons [10]. In fact the use of spoken phrases to convey messages and communicate information to users has been seen as an advantage over the use of te xt alone [37, 38]. The use of non-speech sounds has also proven its usefulness to indicate the occurrence of events and to supplement the visual-only interfaces [39]. Finally, the use of Avatars during E-Commerce interaction has been shown to have a positive effect in experimental studies [40]. However, evaluation of whether this technology should be put into existing E-Commerce practices is under investigation. In particular, the evaluation involved assessing the compliance of existing practices, if any, with empirically derived guidelines for the use of Avatars. In summary, the interaction factor was evaluated in terms of adoption of multimedia, adaptability, self-adaptation, the use of audio and the use of Avatars.

Customer-focus [10] was evaluated using five indicators: feedback mechanisms, help and support, loyalty programmes, purchasing facilities and reliability $[10,27,42]$. First, feedback mechanisms referred to the customer ability to provide the website with opinions, complaints and suggestions [10]. This indicator examined whether the website offered multiple communication channels to facilitate sharing of customer opinions. Secondly, the loyalty programmes indicator considered the effort made by the website to acquire new customers and retain existing ones [10]. For example, rewards were offered for newly joined customers, repeated purchases or customer engagement in product or service improvement. Thirdly, the help and support indicator suggested four key checklists: help function, internal search, FAQs and how-to-do videos [9, 42]. These checklists examined how the customer was supported to accomplish necessary tasks and find relevant information. Fourthly, the purchasing facilities indicator incorporated four checklists: the presentation of return and refund policies, follow-up services, Electronic Receipts (E-Receipt) and item disputes $[9,27]$. These checklists allowed the customer to track orders or claim that ordered items were different from those presented on the website. It also contributed towards raising customer awareness of the purchasing process and overall confidence on the website. Finally, reliability was evaluated by three checklists: efficiency, multi-browser support and availability [10, 27]. In fact, the website should work properly under different screen settings and with multiple browsers, download interface elements, be 
faster and be available 24 hours a day and 7 days a week. In summary, customer-focus was evaluated by the availability of feedback mechanis ms, help and support, loyalty programmes, purchasing facilities and reliability of the website.

Assurance [9] was another factor evaluated by four indicators: trust, security, privacy and authority $[9,10$, 16, 27]. First, the trust indicator examined the legitimacy, reputation of the website and other trustrelated services, such as the Electronic Payment (EPayment) system and customer awareness [9, 10]. In fact, dig ital certificates and trust seals, such as VeriSign, should be presented. Reputation of the website, as well as the E-Payment system comprised other important checklists. In addition, the website should present a brief description of potential threats to raise customer awareness. Secondly, the security indicator was evaluated in terms of the security policy and the presentation of a small padlock or HTTPS in the address bar to indicate the use of Secure Sockets Layer (SSL) encryption [16, 27]. It also involved evaluating whether the website supported a particular password system. Thirdly, privacy evaluated whether the website provided the user with the confidence that personal information would not be handled by unauthorized persons and behaviour was not monitored by cookies or any other means [9, 27]. The website should also present third party privacy seals and a privacy policy. Finally, the authority indicator was evaluated through three checklists: information about the organization and website manager, content creditability and copyrights [10]. In fact, the website should identify the content creditability to increase the user's confidence regarding content. In addition, the website should provide information about the organization's physical address and identification of copyrights. It should also present necessary information related to the website manager, such as E-Mail. In brief, this factor, i.e. assurance, was assessed by trust, security, privacy and authority indicators.

\section{Experimental Study}

Saudi Arabia is regarded as the largest Information and Communication Technology (ICT) market in the region, as it accounts for over $40 \%$ of regional IT spending [43]. In 2007, it was estimated that the IT product market in Saudi Arabia was over \$3 billion [43]. In addition, ICT services, internet users and PC sales have been growing rapidly in Saudi Arabia [44, 45], compared to other countries in the region. With this widespread use of ICT services, Saudi Arabia has witnessed improved quality of the ICT infrastructure and public awareness of the internet. Furthermore, a report by the Arab Advisors Group [46] revealed the high potential of E-Commerce in Saudi Arabia, revealing that the ICT sector in Saudi Arabia is growing rapidly at rate of $9.3 \%$. It also showed that over $14 \%$ of the population in Saudi Arabia is engaged in E-
Commerce activities. The report estimated that ECommerce spending in Saudi Arabia has reached over 12 Billion Riyals and it considered the E-Commerce market in Saudi Arabia to be the largest in the Arab world. Therefore, it can be said that Saudi Arabia is one of the best ICT investment environments with great ECommerce potential compared to the other countries in the Middle East.

Although the potential of E-Commerce is recognized, its adoption in Saudi Arabia faces several limitations and challenges, such as the poor regulatory environment and immature supplementary services, as well as other cognitive and social issues [44, 47, 48]. Based on two ICT adoption models, adoption of E-Commerce has been assessed by Sait et al. [49] who studied the internet's influence on social response and behaviour in Saudi Arabia. The study relied on the user's perception of influential E-Commerce factors to draw conclusions related to the status of E-Commerce. In addition, AlOtaibi and Al-Zahrani [47] carried out an investigation into the tendency towards adopting E-Commerce in Saudi Arabia by evaluating the commercial web presence of 134 organizations from different sectors. This investigation relied on four evaluation factors: marketing, interaction, knowledge and commerce. The study revealed that marketing, buying and selling features and knowledge utilization were generally poor, whereas interaction was well-managed and appearance of the websites was attractive. More recently, an investigation by Al-Somali et al. [50] into the adoption of E-Commerce in Saudi Arabia revealed that the customer's readiness for online shopping as well as ECommerce practice is yet to mature. In summary, little attention has been paid to the evaluation of ECommerce websites in Saudi Arabia in recent years. The potential of E-Commerce in Saudi Arabia was well recognized in the current literature, but not empirically evaluated.

\subsection{Evaluated Websites}

The selection of websites for evaluation was influenced by the aims and objectives of this study. In particular, the determination of the current status and position of the Saudi commercial web presence, in comparison with global and regional practices was considered. Therefore, the scope of evaluation was extended to include websites with global and regional E-Commerce perspectives to facilitate the comparis on between E-Commerce websites in Saudi Arabia and international key players in the field. As a result, evaluated websites were categorized into three classes: international, regional and domestic. Considered as a benchmark, the international websites were A mazon [51] and Alibaba [52]. A mazon was founded in 1995 as a major player in the E-Commerce field. It sells millions of products to a wide range of diverse customers from different countries. It is seen as one of the most successful and famous E-Commerce websites and some consider it as a best practice example or the best in class. 
Alibaba is one of the key global E-Commerce players owned by the biggest internet groups in China. Although the website offers buying and selling features, evaluating the website was restricted to the process of buying. It was noteworthy that evaluating Alibaba alongside Amazon was considered to add a perspective, because Amazon reflected the Western perspective of E-Commerce, while A libaba showed how E-Commerce is put into practice in the East. In summary, key players in global E-Commerce were benchmarked and included within the evaluated website for comparis on purposes.

There were two regional websites: Souq [53] and Logta [54], while the domestic websites were E-Mall [55] and the E-Market [56]. With a regional ECommerce view, Souq was launched in 2005 to target customers in five Arab countries. The website presents information using Arabic language which leads to the assumption that it only targets Arabic online shoppers. Although the website allows the customer to sell their goods, only the buying process was considered for evaluation. Logta is a B2C E-Commerce website initiated with a regional perspective by a company located in Saudi Arabia (Danat Company). The website sells different products, with a particular focus on hightech products due to high demand in the region. The number of visitors and executed purchase transactions suggested that the website is in the middle-range class. In the domestic category, E-Mall is an E-Commerce project in itiated by a governmental corporation in Saudi Arabia (i.e. Saudi post authority). The website sells a wide range of product types to customers, with a particular focus on those living inside Saudi Arabia. The website utilized the postal and delivery services offered by its owner as an advantage over its competitors. E-Market is another domestic ECommerce website which was launched in 2009 by the Future ICT establishment. It sells ICT related products and services using different marketing techniques and payment methods. In brief, the regional and domestic websites are hosted by organizations located in Saudi Arabia: regional websites targeted customers within and across the country borders; while domestic websites targeted customers inside the country.

\subsection{Evaluation Procedure}

A group of sixty participants $(n=60)$ with excellent experience in web design were recruited to conduct the website evaluation based on a within-participants design [57]. Prior to the evaluation, training sessions were offered to explain the way in which the websites should be evaluated. A pilot study was conducted to explore difficulties of evaluation and to allow the evaluators to be initially engaged in the evaluation activities. Several notes were raised and many unclear points were highlighted. The pilot study produced a revised version of the evaluation process and activities. This involved the inclusion of several items and modification of the ways by which items were evaluated. Upon completion of the preparatory stage, the actual evaluation was individually conducted by the evaluators. Subsequently, under the supervision of the author, peer-review was carried out to resolve conflicting evaluation results. Having browsed each website, items were rated by a five-point scale ranging from not applicable (0) to very strong (4). The scale forced the evaluators to decide whether the item was not applicable, very weak, weak, strong or very strong, as it didn't include an undecided answer. During the evaluation, the perspective of the buyers was considered regardless of the services offered by the website or the type of products it sells. Upon completion of rating the items, a scoring approach, known as the System Usability Scale (SUS) [58], was used to produce an overall score for each factor. In summary, a great deal of effort was put towards ensuring the consistency of website evaluation among all evaluators.

\section{Results}

The sample consisted of 60 participants selected randomly from the population based on a conveniencesampling method, which targets a captive audience [59]. The sample was balanced between male and female as well as undergraduate students, postgraduate students and practitioners. In fact, $50 \%$ of the participants were female and $50 \%$ were male. In addition, the participants represented three groups: undergraduate students (20 participants, 33.33\%), post-graduate students (20 participants, $33.33 \%$ ) and practitioners (20 participants, $33.33 \%)$. Each group consisted of 10 male and 10 female participants. This would counterbalance the effect of gender, education and experience.

Data analysis utilized several statistical tests using the SPSS statistical package. To assess missing data, frequency analysis was used to examine the data appropriateness of each factor. Results from frequency analysis showed that data within each factor was appropriate, which led to the commencing of the analysis phase. Subsequently, the research instrument was validated by reliability and validity tests, such as Cronbach's alpha [60], Composite Reliability (CR) [61] and Average Variance Extracted (A VE) [61]. Statistical tests indicated the validity of the research instrument items as shown in the appendix. The appendix shows psychometric properties and discriminate validity of the constructs. As a result of the instrument validation, an indicator was excluded from the interaction factor, namely, the use of Avatars, due to the low item loading. This indicator had a low loading value because it was not applicable in all websites. Therefore, it can be said that Avatar technology was not adopted in current Ecommerce practices.

Fig. 1 shows the mean values for overall web presence for the evaluated websites, according to website category (a) and individual website (b). At a glance, domestic web presence was assessed to be of lower quality, compared with global and regional web 
presences. In Fig. 1 (a), it can be seen that international web presence scored $81 \%$. It can be seen also that regional web presence scored $60 \%$, which indicated an acceptable level of assessment regarding its ECommerce implementation. On the other hand, domestic web presence scored the lowest value with $52 \%$, which was $8 \%$ and $29 \%$ lower than regional and international web presences respectively. In Fig. 1 (b), it can be seen that Amazon scored the highest assessment value among the six websites with $87 \%$, which was regarded to be an excellent score. Alibaba scored a very good web presence score with $74 \%$, wh ich lay between the Amazon score and the regional website scores. Both Logta and Souq scored an acceptable level of ECommerce web presence with $59 \%$ and $60 \%$ respectively. E-Mall's assessment was similar to that of the regional websites, while E-Markets scored the lowest score among the six websites with $48 \%$. In summary, it can be seen from the figure that the quality of international web presence outweighed that of both regional and domestic web presence.

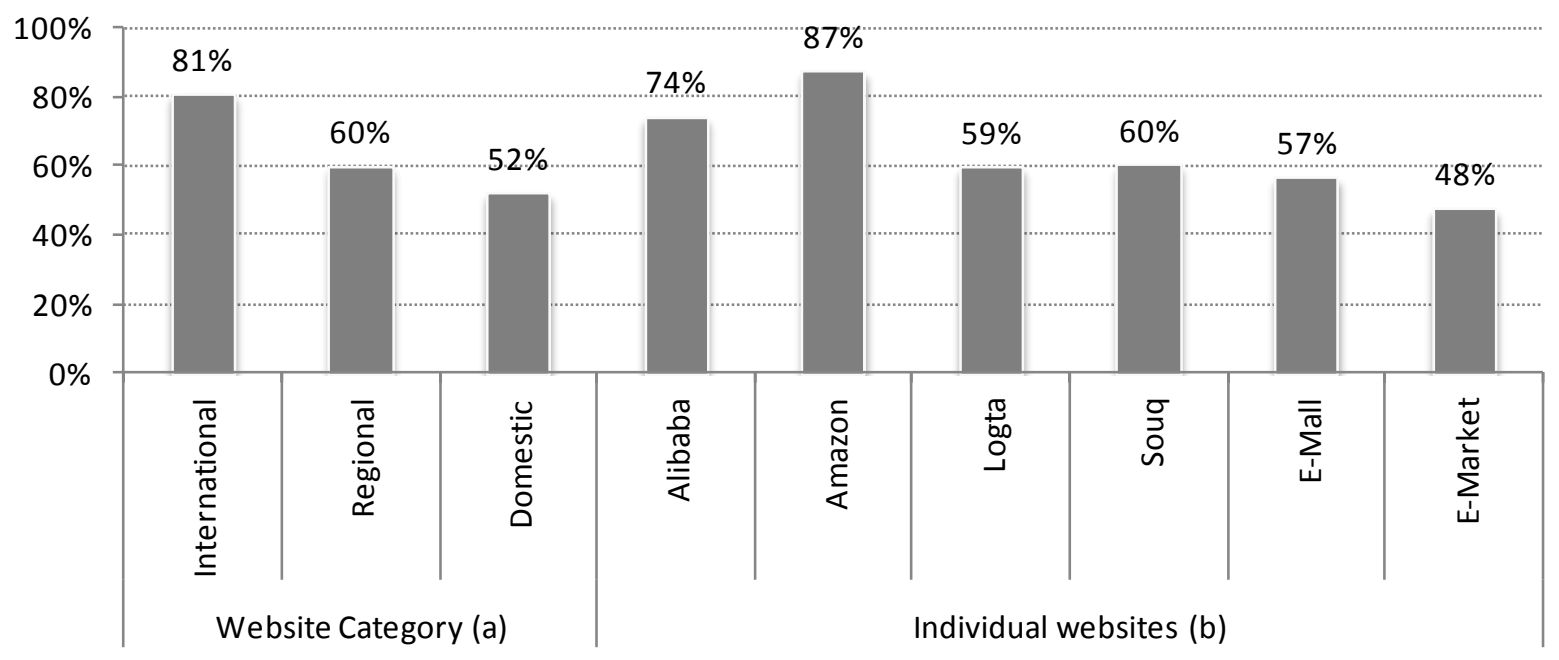

Fig 1: Mean values of overall website evaluation according to website category (a) and individual website (b)

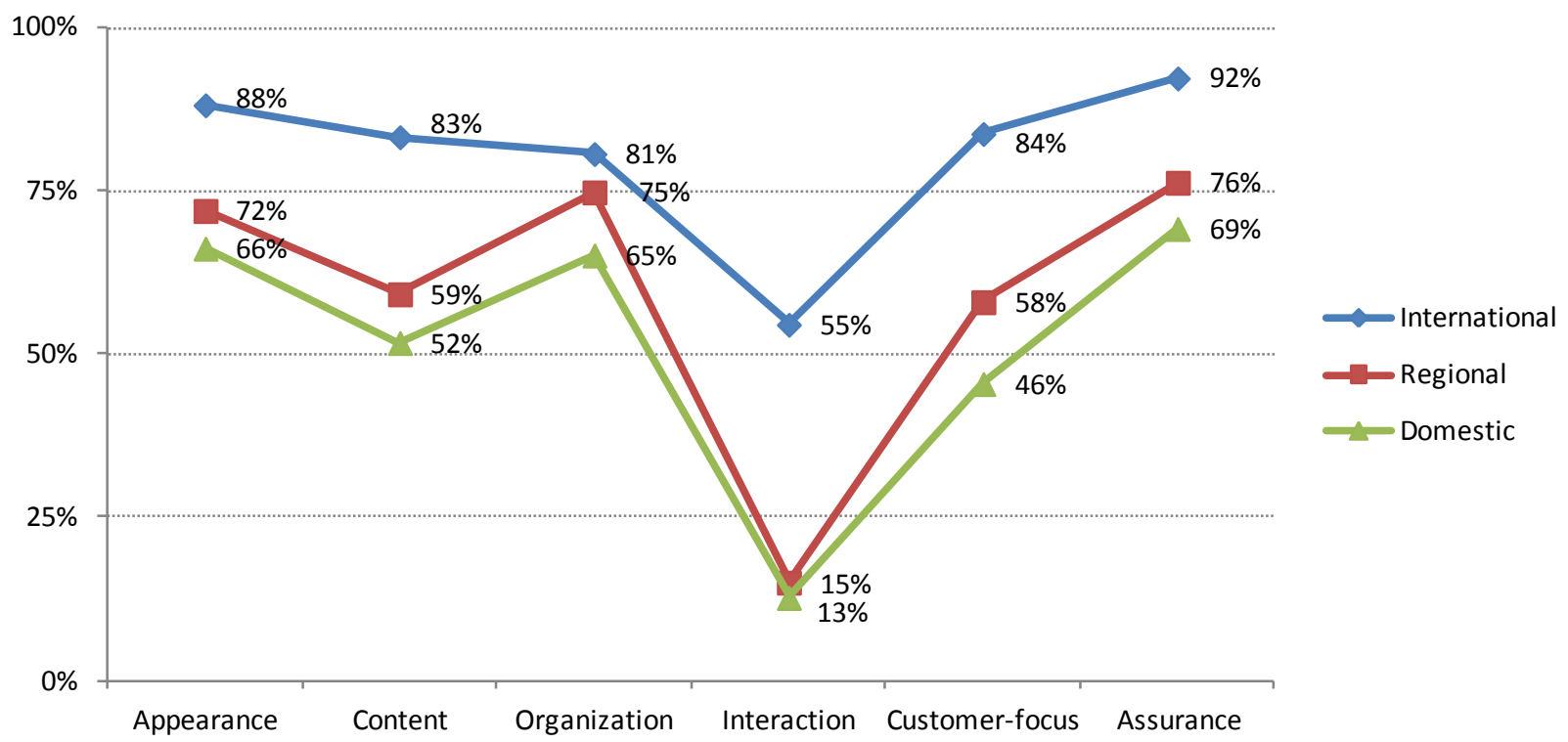

Fig. 2: Profiles of website categories: international, regional and domestic

Fig. 2 shows profiles of website categories: international, regional and domestic, according to the evaluation factors: appearance, content, organization, interaction, customer-focus and assurance. Overall, it can be noticed that international web presence outweighed both regional and domestic web presence with regard to all web evaluation factors. International websites were shown to have an excellent appearance with an $88 \%$ score, compared to an acceptable level of appearance for regional and domestic websites, which scored $72 \%$ and $66 \%$ respectively. 
Regarding the quality of the provided content, it can be seen that the quality of content provided by the regional websites was $31 \%$ lower than that for international websites. Little difference was found between the content quality provided by regional and domestic websites. In terms of website organization, the scores were $81 \%, 75 \%$ and $65 \%$ for international, domestic and regional websites respectively. In addition, the average score for website interaction for international web presence $(55 \%)$ was far greater than that for regional and domestic websites (respectively $15 \%$ and $13 \%$ ). In the customer-focus domain, the difference between international and regional web presence was found to be relatively similar to that for quality of content (i.e. second factor). The score for domestic websites was almost half that for international websites and $12 \%$ lower than that for regional websites. In website assurance, the score of assurance for international websites was $16 \%$ and $23 \%$ higher than for regional and domestic websites, respectively. In summary, apart from website organization, international web presence was by far of higher quality, compared with regional and domestic websites.

Fig. 3 shows profiles of three selected websites: Amazon, E-Mall and E-Market, according to the six web evaluation factors: appearance, content, organization, interaction, customer-focus and as surance. At a glance, it can be seen that there is a huge gap between Amazon's profile and the profiles for E-Mall and E-Market.

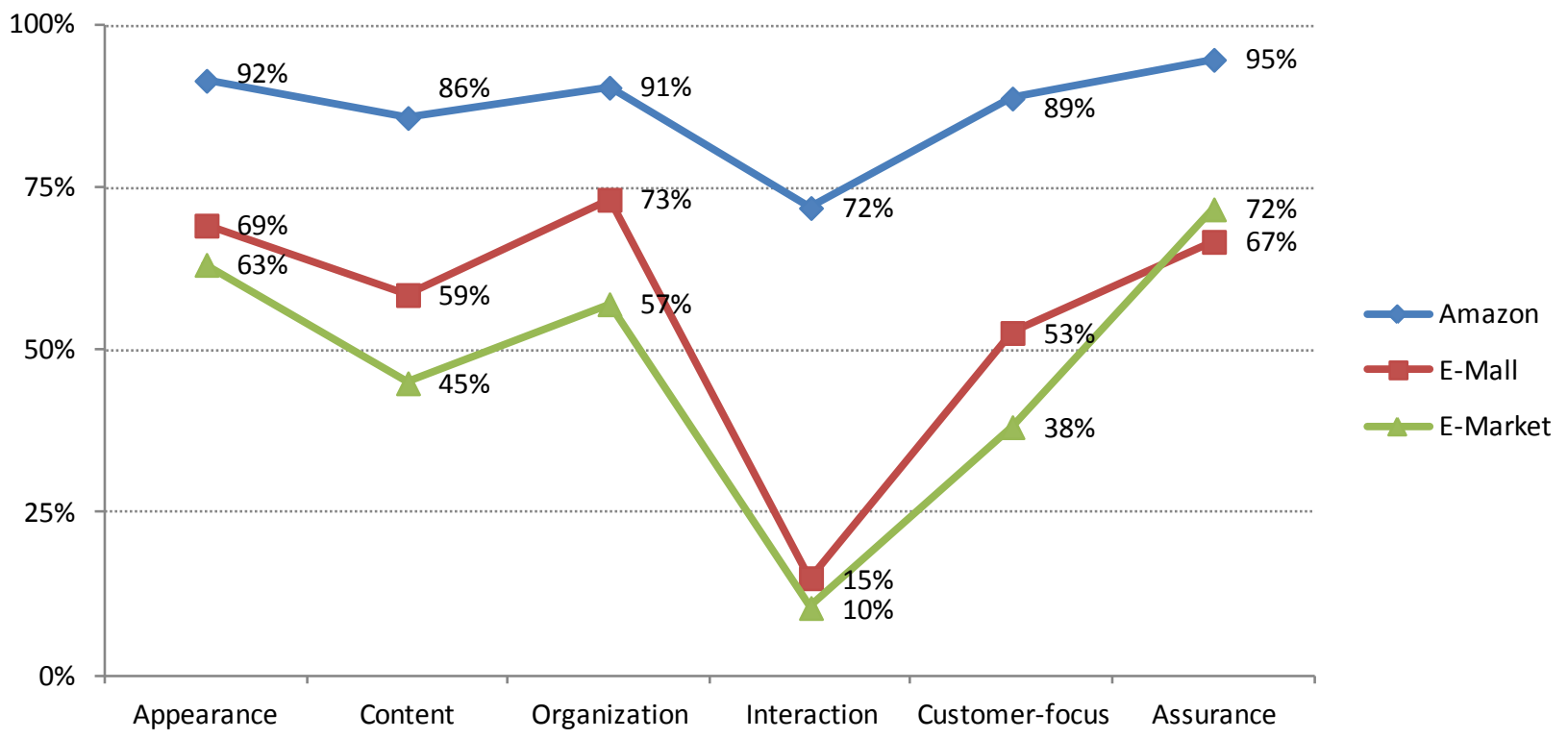

Fig. 3: Profiles of three selected websites: Amazon, E-Mall and E-Market

The appearance of Amazon, for example, was evaluated to be $23 \%$ and $29 \%$ higher than E-Mall and E-Market, respectively. The evaluation also found that the quality of E-Mall and E-Market contents were $27 \%$ and $41 \%$ lower than for A mazon. It can be noticed also that the score for the E-Mall organization (73\%) was right in the middle between A mazon and E-Market with $91 \%$ and $57 \%$ scores, respectively. In addition, a remarkable difference was found between Amazon and the two domestic websites with regard to website interaction. The score for website interaction for Amazon was more than fourfold (E-Mall) and sevenfold (E-Market) that of the domestic websites. The quality of customer service provided by Amazon was more than twice that provided by E-Market. Furthermore, A mazon, with a $95 \%$ assurance score, was assessed to be $23 \%$ and $28 \%$ better than E-Market and E-Mall respectively. In summary, great differences in the quality of web presence was identified, where A mazon was of a higher quality than the two domestic websites: E-Mall and EMarket.
Table 2 reviewed inferential statistics using paired $t$ test and repeated-measures ANOVA. In the withinparticipants design, a paired t-test is useful for examining the difference in parametric variables between two conditions [62]. If the number of conditions are more than two, repeated-measures ANOVA is more useful for examining the difference in parametric variables [63]. In this investigation, paired ttest was used to examine the statistical significance between two conditions and repeated-measures ANOVA to examine the difference among the three conditions. The critical values for t-test and ANOVA were 1.980 and 3.95 respectively. All results were found to be significant, except those which compared the quality of interaction between regional and domestic websites. 
Table 2: Review of Inferential Statistics Using Paired T-Test and Repeated-Measures ANOVA

\begin{tabular}{|c|c|c|c|c|}
\hline \multirow{2}{*}{ Variable } & \multirow{2}{*}{ Examined conditions } & \multicolumn{2}{|c|}{ Significant } & \multirow{2}{*}{ Notes } \\
\hline & & Yes & No & \\
\hline \multirow{4}{*}{$\begin{array}{l}\text { Average score of } \\
\text { overall web } \\
\text { presence }\end{array}$} & Among all conditions & $\sqrt{ }$ & & $\mathrm{F}(357)=257.5, \mathrm{p}<0.001$ \\
\hline & International versus domestic web presence & $\sqrt{ }$ & & $\mathrm{t}_{119}=21.1, \mathrm{p}<0.001$ \\
\hline & International versus regional web presence & $\sqrt{ }$ & & $\mathrm{t}_{119}=20.1, \mathrm{p}<0.001$ \\
\hline & Regional versus domestic web presence & $\sqrt{ }$ & & $\mathrm{t}_{119}=7.9, \mathrm{p}<0.001$ \\
\hline \multirow{4}{*}{$\begin{array}{c}\text { Website } \\
\text { appearance }\end{array}$} & Among all conditions & $\sqrt{ }$ & & $\mathrm{F}(357)=127.7, \mathrm{p}<0.001$ \\
\hline & International versus domestic web presence & $\sqrt{ }$ & & $\mathrm{t}_{119}=14.1, \mathrm{p}<0.001$ \\
\hline & International versus regional web presence & $\sqrt{ }$ & & $\mathrm{t}_{119}=15.8, \mathrm{p}<0.001$ \\
\hline & Regional versus domestic web presence & $\sqrt{ }$ & & $\mathrm{t}_{119}=4.7, \mathrm{p}<0.001$ \\
\hline \multirow{4}{*}{ Website conten ts } & Among all conditions & $\sqrt{ }$ & & $\mathrm{F}(357)=201.3, \mathrm{p}<0.001$ \\
\hline & International versus domestic web presence & $\sqrt{ }$ & & $\mathrm{t}_{119}=18.9, \mathrm{p}<0.001$ \\
\hline & International versus regional web presence & $\sqrt{ }$ & & $\mathrm{t}_{119}=19.9, \mathrm{p}<0.001$ \\
\hline & Regional versus domestic web presence & $\sqrt{ }$ & & $\mathrm{t}_{119}=5.1, \mathrm{p}<0.001$ \\
\hline \multirow{4}{*}{$\begin{array}{c}\text { Website } \\
\text { organization }\end{array}$} & Among all conditions & $\sqrt{ }$ & & $\mathrm{F}(357)=40.4, \mathrm{p}<0.001$ \\
\hline & International versus domestic web presence & $\sqrt{ }$ & & $\mathrm{t}_{119}=4.2, \mathrm{p}<0.001$ \\
\hline & International versus regional web presence & $\sqrt{ }$ & & $\mathrm{t}_{119}=7.6, \mathrm{p}<0.001$ \\
\hline & Regional versus domestic web presence & $\sqrt{ }$ & & $\mathrm{t}_{119}=7.1, \mathrm{p}<0.001$ \\
\hline \multirow{4}{*}{$\begin{array}{l}\text { Website } \\
\text { interaction }\end{array}$} & Among all conditions & $\sqrt{ }$ & & $\mathrm{F}(357)=268.9, \mathrm{p}<0.001$ \\
\hline & International versus domestic web presence & $\sqrt{ }$ & & $\mathrm{t}_{119}=18.6, \mathrm{p}<0.001$ \\
\hline & International versus regional web presence & $\sqrt{ }$ & & $\mathrm{t}_{119}=17.7, \mathrm{p}<0.001$ \\
\hline & Regional versus domestic web presence & & $\sqrt{ }$ & $\mathrm{t}_{119}=1.9, \mathrm{p}>0.05$ \\
\hline \multirow{4}{*}{ Customer-focus } & Among all conditions & $\sqrt{ }$ & & $\mathrm{F}(357)=304.1, \mathrm{p}<0.001$ \\
\hline & International versus domestic web presence & $\sqrt{ }$ & & $\mathrm{t}_{119}=20.9, \mathrm{p}<0.001$ \\
\hline & International versus regional web presence & $\sqrt{ }$ & & $\mathrm{t}_{119}=24.0, \mathrm{p}<0.001$ \\
\hline & Regional versus domestic web presence & $\sqrt{ }$ & & $\mathrm{t}_{119}=9.9, \mathrm{p}<0.001$ \\
\hline \multirow{4}{*}{$\begin{array}{l}\text { Website } \\
\text { assurance }\end{array}$} & Among all conditions & $\sqrt{ }$ & & $\mathrm{F}(357)=88.2, \mathrm{p}<0.001$ \\
\hline & International versus domestic web presence & $\sqrt{ }$ & & $\mathrm{t}_{119}=16.3, \mathrm{p}<0.001$ \\
\hline & International versus regional web presence & $\sqrt{ }$ & & $\mathrm{t}_{119}=15.0, \mathrm{p}<0.001$ \\
\hline & Regional versus domestic web presence & $\sqrt{ }$ & & $\mathrm{t}_{119}=5.0, \mathrm{p}<0.001$ \\
\hline
\end{tabular}

\section{Discussion}

Web evaluation is becoming more mature, addressing the needs of both researchers and practitioners. The evaluation of commercial web presence is essential in order to gain a full understanding of the ever-changing environments of E-Commerce. This paper assessed commercial web presence in Saudi Arabia in relation to global key players and regional practices. Assessment of E-Commerce websites suggested three categories: international, regional and domestic. Results herein revealed that Saudi commercial web presence is yet to mature, compared with international E-Commerce presence. Largely, the average score for overall web presence for international websites indicated a very high level of implementation of E-Commerce practices. This can be attributed to the fact that international websites fulfilled most of the evaluation checklists. Organization of the websites showed a relatively different picture, as the difference between international and regional websites $(6 \%)$ was found to be the lowest among all web evaluation factors. This can be attributed to the weak website identity of international websites, where the website names (i.e. A mazon and Alibaba) did not reflect the main purpose of the website. In contrast, the website names for regional (i.e. Souq and Logta) and domestic websites (i.e. E-Mall and E-Market) had a strong relationship with the main website purpose. Otherwise, websites demonstrated excellent levels of organization, especially organization of product categories. Website interaction was found to be the lowest rated factor among all web evaluation criteria, due to the rare use of multimedia elements and interactive features. It can be noticed that interaction was acceptable for international websites with $55 \%$, while it was poor for regional and domestic websites with $15 \%$ and $13 \%$, respectively.

It was noteworthy that the interaction score for domestic web presence was the lowest score among all observations whereas the highest value among all factors was scored for the level of assurance provided by international websites with $92 \%$. Furthermore, it can 
be said that Avatars and speaking characters were not utilized in current E-Commerce practices, although these were revealed to have great potential in the experimental settings. In summary, it can be concluded that the E-Commerce presence in Saudi Arabia was of a lower quality than international E-Commerce presence.

A comparison between the two domestic websites and Amazon was provided to highlight several areas of potential improvement. Overall, results showed a huge gap between the Amazon profile and those for E-Mall and E-Market. This indicates that considerable improvement is needed by the two domestic websites in order to reach a similar quality level to that of international websites. The huge difference in interaction can be attributed to the maturity of Amazon's interactive features, such as intelligent recommendations, adaptive content and the adoption of multimedia. In addition, the customer-focus result for Amazon was twice that of E-Market. This indicates that E-Market managers should at least double the effort put into the implementation of customer feedback mechanis ms, help and support, loyalty programmes, purchasing facilities and reliability. E-Mall managers also need to increase the focus on customers by at least $36 \%$, especially in terms of adopting more effective loyalty programmes. Amazon's assurance was also shown to be remarkably different ranging from $23 \%$ to $27 \%$ when compared with E-Market and E-Mall. Therefore, it can be said that an improvement of at least $23 \%$ is needed in the assurance provided by E-Mall and E-Market, including trust, security, privacy and authority. In summary, apart from interaction, E-Mall needs to improve by 25-35\% and E-Market requires 23$40 \%$ improvement in all aspects of web evaluation factors. Interaction needs to be radically improved for both websites, due to the huge gap between their scores and that for Amazon.

Several limitations were encountered, such as female participation, the adequacy of sample size, the changing nature of E-Commerce websites and unifying evaluators' perspectives. Due to social concerns, female participation was one of the barriers that delayed the evaluation. Although sixty participants $(n=60)$ comprises a low sample size, the nature of this study limited the opportunity to increase the sample size, as it required extensive training for the participants and unification of the evaluation pers pectives. For example, because evaluated websites were changing rapidly, it was necessary for evaluators to conduct the evaluation over a short period of time. It was also necessary to resolve conflicting evaluations among participants. For example, evaluation of loyalty programmes was one of the most contradictory indicators, as some participants gave this a very high evaluation score, while others claimed that it was not adopted by a particular website. Our experience in this experiment suggested that such conflicts can be resolved by peer review, due to the gap in participants' perceptions of the indicators. This issue, with difficulties as sociated with female communications, changing environments and time constraints, limited the chance of increasing the sample size. In summary, due to its nature, this investigation faced several barriers related to the sample size and the evaluation process.

Experience gained from this study sugges ts that managers of Saudi websites should consider the best practice/best-in-class websites in order to reach the quality levels of international websites. It is thought that Saudi commercial web presence requires an improvement of $25-40 \%$ in its appearance, content, organization, customer-focus and assurance, which represents the gap between the domestic websites' web presence and Amazon. It also recommends rethinking the way customers interact with Saudi commercial websites, as a huge gap exists between its interaction performance and that for international E-Commerce websites. Furthermore, this study revealed that Avatar technology is yet to be considered in the E-Commerce field, as it was found that this technology was not utilized at all on domestic, regional or international websites. This study will be useful for managers and web designers in Saudi E-Commerce companies because it highlights several quality improvement areas, however, study into the effect of E-Commerce organizational issues and regulatory environments in Saudi Arabia would merit further investigation.

\section{Conclusion}

Web evaluation is a very basic method of ECommerce presence assessment. In this study, web evaluation was adopted to investigate the quality of ECommerce web presence in three categories: international, regional and domestic. Based on models and methods of web evaluation in the current literature, a proposed research instrument was introduced. The instrument measured six key factors: appearance, content, organization, interaction, customer-focus and assurance. Each factor was observed using several indicators. The actual website evaluation considered six websites: Amazon, Alibaba, Souq, Logta, E-Mall and E-Market. Saudi Arabia was selected as an application domain, as two Saudi E-Commerce websites were included within the domestic website category. Regional websites were also considered to be located in Saudi Arabia, but had a regional view (i.e. websites in different countries in the region). Indeed, international key players in the E-Commerce field, such as Amazon, were introduced as a benchmark to facilitate effective comparison. In the empirical investigation, sixty $(n=60)$ participants undertook the actual web presence evaluation by assessing each indicator for each website. Results therein suggested that international web presence was of higher quality, compared with regional and domestic web presence with regard to all aspects of web evaluation. Apart from interaction, the quality of regional web presence also outweighed that for domestic web presence with regard to web evaluation aspects. 


\section{References}

[1] B. Bai, R. Law, and I. Wen, "The impact of website quality on customer satisfaction and purchase intentions: Evidence from Chinese online visitors," International Journal of Hospitality Management, vol. 27, pp. 391-402, 2008.

[2] N. Avouris, N. Tselios, C. Fidas, and E. Papachristos, "Website evaluation: A usabilitybased perspective," Advances in Informatics, pp. 165-183, 2003.

[3] W. C. Chiou, C. C. Lin, and C. Perng, "A strategic framework for website evaluation based on a review of the literature from 1995-2006," Information \& management, vol. 47, pp. 282-290, 2010.

[4] E. Loiacono, R. Watson, and D. Goodhue, "WebQual: An instrument for consumer evaluation of web sites," International Journal of Electronic Commerce, vol. 11, pp. 51-87, 2007.

[5] Buyukozkan G., Ruan D., and Feyzioglu O., "Evaluating e-learning web site quality in a fuzzy environment," International Journal of Intelligent Systems, vol. 22, pp. 567-586, 2007.

[6] C. Stracke and B. Hildebrandt, "Quality development and quality standards in e-learning: adoption, implementation, and adaptation," in World Conference on Educational Multimedia, Hypermedia and Telecommunication, Chesapeake, VA, USA, 2007, pp. 4158-4165.

[7] R. Law, S. Qi, and D. Buhalis, "Progress in tourism management: A review of website evaluation in touris m research," Tourism Management, vol. 31, pp. 297-313, 2010.

[8] W. Tsai, W. Chou, and C. Lai, "An effective evaluation model and improvement analysis for national park websites: A case study of Taiwan," Tourism Management, vol. 31, pp. 936-952, 2010.

[9] F. Lin, K. Huarng, Y. Chen, and S. Lin, "Quality evaluation of web services," in IEEE International Conference on E-Commerce Technology for Dynamic E-Business Beijing,China: IEEE, 2004, pp. 226-233.

[10] R. Fitzpatrick, "Additional quality factors for the World Wide Web," in the 2nd World Congress for Software Quality Japan, 2000.

[11] L. Mich, M. Franch, and L. Gaio, "Evaluating and designing Web site quality," Multimedia, IEEE, vol. 10, pp. 34-43, 2003.

[12] Z. Yang, R. T. Peterson, and S. Cai, "Services quality dimensions of Internet retailing: an exploratory analysis," Journal of services marketing, vol. 17, pp.685-700, 2003.
[13] A. Parasuraman, V. A. Zeithaml, and L. L. Berry, "Servqual," Journal of retailing, vol. 64, pp. 12-37, 1988.

[14] E. T. Loiacono and R. T. Director-Watson, "Webqual: a web site quality instrument," Athens, GA, USA: University of Georgia, 2000.

[15] S. Barnes and R. Vidgen, "Assessing the quality of auction web sites," in the 34th Annual Hawaii International Conference on System Sciences Hawaii: IEEE, 2001.

[16] S. J. Barnes and R. T. Vidgen, "An integrative approach to the assessment of e-commerce quality," Journal of Electronic Commerce Research, vol. 3, pp. 114-127, 2002.

[17] M. Long and C. McMellon, "Exploring the determinants of retail service quality on the Internet," Journal of services marketing, vol. 18, pp. 78-90, 2004.

[18] H. Li and R. Suomi, "A proposed scale for measuring e-service quality," International Journal of u-and e-Service, Science and Technology, vol. 2, pp. 1-10, 2009.

[19] Z. Yang, M. Jun, and R. T. Peterson, "Measuring customer perceived online service quality: scale development and managerial implications," International Journal of Operations \& Production Management, vol. 24, pp. 1149-1174, 2004.

[20] P. Schubert, "Extended Web Assessment Method (EWAM): Evaluation of Electronic Commerce Applications from the Customer's Viewpoint," International Journal of Electronic Commerce, vol. 7, pp. 51-80, 2002.

[21] D. Selz and P. Schubert, "Web Assessment- A Model for the Evaluation and the Assessment of Successful Electronic Commerce Applications," Electronic Markets, vol. 7, pp. 46-48, 1997.

[22] F. Davis, "A technology acceptance model for empirically testing new end-user information systems: theory and results," in Sloan School of Management. vol. PhD: Massachusetts Institute of Technology, 1986.

[23] Z. Yang and M. Jun, "Consumer perception of eservice quality: from internet purchaser and nonpurchaser perspectives," Joumal of Business Strategies, vol. 19, pp. 19-41, 2002.

[24] J. E. Collier and C. C. Bienstock, "Measuring service quality in e-retailing," Journal of Service Research, vol. 8, pp. 260-275, 2006.

[25] F. B. Tan and L. L. Tung, "Exploring website evaluation criteria using the repertory grid technique: A web designers perspective," in the second annual workshop on HCI research in MIS, 2003, pp. 65-69. 
[26] W. C. Chiou, C. C. Lin, and C. Perng, "A strategic website evaluation of online travel agencies," Tourism Management, 2011.

[27] A. Basu, "Context-driven assessment of commercial web sites," in the 36th Annual Hawaii International Conference on System Sciences Hawaii: IEEE, 2003.

[28] A. Parasuraman, "ES-QUAL: A multiple-item scale for assessing electronic service quality," Journal of Service Research, vol. 7, pp. 213-233, 2005.

[29] E. Diniz, R. M. Porto, and T. Adachi, "Internet banking in Brazil: evaluation of functionality, reliability and usability," The Electronic Journal of Information Systems Evaluation, vol. 8, pp. 41-50, 2005.

[30] L. Hasan and E. Abuelrub, "Assessing the quality of web sites," Applied Computing and Informatics, vol. 9, pp. 11-29, 2011.

[31] S. Y. Chen and R. D. Macredie, "The assessment of usability of electronic shopping: a heuristic evaluation," International Journal of Information Management, vol. 25, pp. 516-532, 2005.

[32] ISO, "Ergonomics of humansystem interaction -Part 151: Guidance on World Wide Web user interfaces," in ISO 9241-151 http://www.iso.org/iso/iso_catalogue/catalogue_tc/ catalogue_detail.htm?csnumber=37031, 2008.

[33] H. Achour and N. Bensedrine, "An evaluation of internet banking and online brokerage in Tunisia," in the 1st International Conference on E-Business and E-learning Amman, Jordan, 2005, pp. 147-158.

[34] O. Signore, "A comprehensive model for web sites quality," in the Seventh IEEE International Symposium on Web Site Evolution: IEEE, 2005, pp. 30-36.

[35] D. Wenham and P. Zaphiris, "User interface evaluation methods for internet banking web sites: a review, evaluation and case study," HumanComputer Interaction, Theory and Practice, pp. 721-725, 2003.

[36] R. A wamleh and C. Fernandes, "Internet Banking: An empirical investigation into the extent of adoption by banks and the determinants of customer satisfaction in the United Arab Emirates," Journal of Internet Banking and Commerce, vol. 10, p. 86, 2005.

[37] D. Rigas and D. Memery, "Utilising audio-visual stimuli in interactive information systems: a two domain investigation on auditory metaphors," in International Conference on Information Technology: Coding and Computing Las Vegas, Nevada, USA, 2002, pp. 190-195.
[38] D. Rigas and A. Stergiou, "An Empirical Approach to Audio-Visual Guided Electronic Commerce," WSEAS Transactions on Computer Research, vol. 2, pp. 177-182, 2007.

[39] D. Rigas and J. Alty, "The rising pitch metaphor: an empirical study," International Journal of Human-Computer Studies, vol. 62, pp. 1-20, 2005.

[40] M. Alotaibi and D. Rigas, "An empirical approach to mu ltimodal customer knowledge management," Intelligent Decision Technologies, vol. 4, pp. 181195, 2010.

[41] B. Yoo and N. Donthu, "Developing a scale to measure the perceived quality of an Internet shopping site (SITEQUAL)," Quarterly Journal of Electronic Commerce, vol. 2, pp. 31-46, 2001.

[42] W. Chung and J. Paynter, "An evaluation of Internet banking in New Zealand," in the 35th Annual Hawaii International Conference on System Sciences (HICSS) Hawaii: IEEE, 2002, pp. 2410-2419.

[43] BMI, "The Saudi Arabia IT Report' ", [Online] http://www.business monitor.co m/it/saudiarabia.ht $\mathrm{ml}$, accessed on 30 January 2012, 2008.

[44] S. I. Alfuraih, "E-Commerce and E-Commerce Fraud in Saudi Arabia: A Case Study," in the International Conference on Information Security and Assurance Busan, Korea: IEEE, 2008, pp. 176-180.

[45] CITC, "IT Report," [Online] http://www.citc.gov.sa/arabic/Reportsandstudies/R eports/Pages/IT-Report.aspx, accessed on 30 January 2012, 2009.

[46] The Arab Advisors Group, "Growth Of KSA's ECommerce Sector " Press Release, Riyadh, Saudi Arabia,

[Online] http://www.middleeastevents.com/site/pres_dtls.as p?pid=7195, accessed on 17 February 20112009.

[47] M. Al-Otaibi and R. Al-Zahrani, "E-commerce adoption in Saudi Arabia: an evaluation of commercial organizatios' web sites," in International Conference on Information Technology in Asia (CITA) Malaysia, 2003.

[48] N. Almojel, "Fostering Trust for Middle-Eastern B2C e-Commerce," in Department of Department of Electronic Imaging and Media Communications (EIMC). vol. PhD Bradford: University of Bradford, 2007.

[49] S. Sait, K. Al-Tawil, and S. Hussain, "E-commerce in Saudi Arabia: Adoption and perspectives," Australasian Journal of Information Systems, vol. 12, 2007.

[50] S. Al-Somali, R. Gholami, and B. Clegg, "An Investigation into the Adoption of Electronic Commerce among Saudi Arabian SMEs," Journal 
of Electronic Commerce in Organizations, vol. 9, pp. 41-65, 2011.

[51] Amazon, "International online Shopping website," http://www.amazon.com/, accessed on 12 December 2011.

[52] Alibaba, "International online shopping website," http://www.alibaba.com/, accessed on 12 December 2011.

[53] Souq, "Regional E-Commerce website," [Online] http://www.souq.com/, accessed on 1-15 December 2011.

[54] Logta, "Regional E-Commerce website," [Online] http://www.logta.com/, accessed on 1-15 December 2011.

[55] E-Mall, "Domestic E-Commerce website," [Online] http://www.e-mall.com.sa/, accessed on 1-15 December 2011.

[56] E-Market, "Domestic E-Commerce website," [Online] http://www.sh4sa.net/, accessed on 1-15 December 2011.

[57] C. Dancey and J. Reidy, "Variables and Research Design," in Statistics without Maths for Psychology: Using SPSS for Windows: Prentice Hall, 2004, pp. 1-33.
[58] J. Brooke, "SUS: a quick and dirty usability scale," Usability Evaluation in Industry, pp. 189-194, 1996.

[59] N. Salkind, "Sampling and Generalizability," in Exploring research, Sixth ed New Jersey, USA: Pearson Education International, 2006, pp. 85-98.

[60] L. J. Cronbach, "Coefficient alpha and the internal structure of tests," Psychometrika, vol. 16, pp. 297 334, 1951.

[61] J. Hair, J. Joseph, R. Anderson, R. Tatham, and W. Black, Multivariate data analysis with readings, 4 ed. New York: Macmillan, 1995.

[62] C. Dancey and J. Reidy, "Analysis of Differences Between Two Conditions: The t-test," in Statistics without Maths for Psychology: Using SPSS for Windows Essex, England: Prentice Hall, 2004, pp. 206-236.

[63] C. Dancey and J. Reidy, "Analysis of Differences Between Three or More Conditions: One-factor ANOVA," in Statistics without Maths for Psychology: Using SPSS for Windows Essex, England: Prentice Hall, 2004, pp. 290-320.

\section{Appendices}

Appendix A: Psychometric properties of the constructs

\begin{tabular}{|c|c|c|c|c|c|}
\hline Construct & Item & Loading & $\begin{array}{c}\text { Cronbach's } \\
\text { Alpha }(\alpha)\end{array}$ & $\begin{array}{c}\text { Composite } \\
\text { Reliability (CR) } \\
\end{array}$ & $\begin{array}{l}\text { Average Variance } \\
\text { Extracted (AVE) }\end{array}$ \\
\hline \multirow{4}{*}{ Appearance } & Attractive appearance & 0.85 & \multirow{4}{*}{0.833} & \multirow{4}{*}{0.892} & \multirow{4}{*}{0.674} \\
\hline & Balanced appearance & 0.86 & & & \\
\hline & The use of colours & 0.81 & & & \\
\hline & The use of text & 0.77 & & & \\
\hline \multirow{5}{*}{ Content } & Updated content & 0.84 & \multirow{5}{*}{0.849} & \multirow{5}{*}{0.892} & \multirow{5}{*}{0.624} \\
\hline & Relevant content & 0.84 & & & \\
\hline & Accurate content & 0.81 & & & \\
\hline & Multilanguage content & 0.79 & & & \\
\hline & Content presentation & 0.66 & & & \\
\hline \multirow{5}{*}{ Organization } & Website identity & 0.87 & \multirow{5}{*}{0.811} & \multirow{5}{*}{0.910} & \multirow{5}{*}{0.671} \\
\hline & Mapping & 0.80 & & & \\
\hline & Consistency & 0.81 & & & \\
\hline & Navigation and links & 0.76 & & & \\
\hline & Index & 0.84 & & & \\
\hline \multirow{4}{*}{ Interaction } & Adoption of multimedia & 0.77 & \multirow{4}{*}{0.873} & \multirow{4}{*}{0.888} & \multirow{4}{*}{0.666} \\
\hline & Adaptability & 0.85 & & & \\
\hline & Self-adaptation & 0.87 & & & \\
\hline & The use audio & 0.76 & & & \\
\hline \multirow{5}{*}{ Customer-focus } & Feedback mechanisms & 0.91 & \multirow{5}{*}{0.895} & \multirow{5}{*}{0.906} & \multirow{5}{*}{0.659} \\
\hline & Loyalty programmes & 0.78 & & & \\
\hline & Help and support & 0.68 & & & \\
\hline & Purchasing facilities & 0.84 & & & \\
\hline & Reliability & 0.84 & & & \\
\hline \multirow{4}{*}{ Assurance } & Trust & 0.85 & \multirow{4}{*}{0.898} & \multirow{4}{*}{0.899} & \multirow{4}{*}{0.691} \\
\hline & Security & 0.77 & & & \\
\hline & Privacy & 0.84 & & & \\
\hline & Authority & 0.86 & & & \\
\hline
\end{tabular}


Appendix B: Discriminate validity of constructs

\begin{tabular}{|c|c|c|c|c|c|c|}
\hline Latent variables & Organization & Appearance & Interaction & Content & Assurance & Customer-focus \\
\hline Organization & 0.819 & & & & & \\
\hline Appearance & 0.751 & 0.821 & & & & \\
\hline Interaction & 0.669 & 0.811 & 0.816 & & & \\
\hline Content & 0.781 & 0.725 & 0.746 & 0.790 & & \\
\hline Assurance & 0.805 & 0.657 & 0.622 & 0.739 & 0.831 & \\
\hline Customer-focus & 0.715 & 0.742 & 0.722 & 0.710 & 0.725 & 0.812 \\
\hline
\end{tabular}

\section{Author Profile}

Mutlaq B. Alotaibi is an Assistant Professor of Information Systems (IS) at Imam University. In 2010, Dr. Alotaibi was appointed Head of the IS department. In 2012, he was appointed as the Vice Dean for Academic Affairs at the College of Computer and Information Sciences. His main research interests are in the area of interactive systems, particularly in multimodal interaction and adaptive user interfaces. He is also interested in IS research, particularly consumer behavior, and in the application of user acceptance of technologies. He has publications in the fields of, customer knowledge management (CKM), customer relationship management (CRM), E-Business and ECommerce, usability testing and usability heuristics.

How to cite this paper: Mutlaq B. Alotaibi,"E-Commerce Adoption in Saudi Arabia: an Assessment of International, Regional and Domestic Web Presence", International Journal of Information Technology and Computer Science(IJITCS), vol.5, no.2, pp.42-56, 2013.DOI: 10.5815/ijitcs.2013.02.05 